\title{
Aspects of Fire Research Activities in Russia
}

\author{
A. KOROLCHENKO \\ All-Russian Research Institute for Fire Protection \\ Settlement VNIIPO 12, Balashikha district, Moscow region, 143900 Russia
}

\begin{abstract}
In December 1994 Russian Federation adopted 'Fire Safety Act' governing legal, economic and social aspects of fire safety in Russia. The Act defines the system of fire safety, specifies the functions of State Fire Service and the duties of state and local fire safety authorities. The adoption of the Act was dictated by unfavorable tendency in growth of number of fires and human victims. For the last years 300 thousand fires take place in Russia annually where 12-13 thousand people die. The research into fire safety problems is mainly performed in the institutions submitted to the Ministry of the Interior (All-Russian Research Institute for Fire Protection, Moscow Fire Safety Institute and the others), in the institutes of the Russian Academy of Sciences (the Institute of Chemical Physics, the Institute of Chemical Kinetics and Combustion and the others), in the universities of the Ministry of Higher Education (Moscow State University, Moscow State Building University, Khabarobsk Polytechnic University and the others). The research is conducted in the following main directions:
\end{abstract}

- fire behaviour of substances, materials, constructions, buildings, structures;

- fire and explosion dynamics in the rooms of buildings, structures, groups of buildings and structures;

- human behaviour, flora and fauna under fire conditions;

- ecological aspects of fire fighting;

- ways, methods and means of fire prevention and suppression;

- arrangement and management of fire prevention and protection activities;

- fire safety economics.

This presentation further introduces the framework, recent results and application of these directions in Russian fire research. 


\section{INTRODUCTION}

\section{General Tendencies and Fire Statistics Russia}

A permanent growth of fires and human victims at fires has been registered lately in Russia. In 70-th and 80-th an annual increase of number of fires constituted about $10 \%$. But in 1994-1995 a certain reduction of fires took place.

Fire data for 1991-1995 is presented in Table 1.

Table 1. Dynamics of the main indices of fire situation in Russia

\begin{tabular}{|l|c|c|c|c|c|}
\hline \multicolumn{1}{|c|}{ Index } & 1991 & 1992 & 1993 & 1994 & 1995 \\
\hline Number of fire & 317500 & 314600 & 332400 & 325200 & 294300 \\
\hline Human victims at fires & 7705 & 10305 & 13712 & 15733 & 14893 \\
\hline Number of the injured & 8503 & 9778 & 11559 & 12200 & 13513 \\
\hline $\begin{array}{l}\text { Number of the ruined } \\
\text { Constructions (thousand) }\end{array}$ & 54.9 & 68.6 & 70.0 & 71.5 & 72.3 \\
\hline
\end{tabular}

$82 \%$ of fires occur in residential buildings, $7 \%$ - in industrial premises, $4 \%$ - in store houses and shops, $4 \%$ - in public buildings (theaters, museums, sports grounds), $3 \%$ - in farms.

The main reasons of fires are: careless use of the open flame; short circuits in electrical equipment and installations; violations of the industrial processes technology; malfunction of the heating devices.

In Russia the total fire losses are not estimated. The direct property losses constituted 890 milliard roubles in 1995.

\section{Fire Safety Act}

In 1994 Russian Federation adopted 'Fire Safety Act' governing legal, economic and social aspects of fire safety in Russia.

The State Fire Service being a part of the Ministry of the Interior controls regulations, standardization and certification in the field of fire safety in Russia.

According to this Act the State Fire Service also coordinates the scientific research in the above-mentioned field.

\section{Fire Research Arrangement}

Fire Research is conducted mainly by the three Ministries, they are: the Ministry of the Interior, Academy of Sciences and the Ministry of Higher Education. 
Within the Ministry of the Interior there are two organizations engaged in fire research: All-Russian Research Institute for Fire Protection (VNIIPO) which is situated in Balashikha, Moscow Region and an educational Institute - Moscow Fire Safety Institute (MIPB) which is situated in Moscow.

Within the Academy of Sciences the following organizations execute mainly fire studies:

- the Institute of Chemical Physics (Moscow);

- the Institute of Chemical Kinetics and Combustion (Novosibirsk);

- the Institute of Structural Macrokinetics (Chernogolovka, Moscow Region).

Within the Ministry of Higher Education the fire research is held mainly by:

- Moscow State Building University;

- Khabarovsk State Polytechnic University;

- Tomsk State University.

The fire safety research results are issued mainly in the following journals:

- 'Fire and Explosion Safety';

- 'Fire Safety, Informatics and Technology';

- 'Physics of Combustion and Explosion';

- 'Physical Chemistry';

- 'Chemical Physics'.

The major volume of fire research is carried out by VNIIPO. The Institute has the following structure:

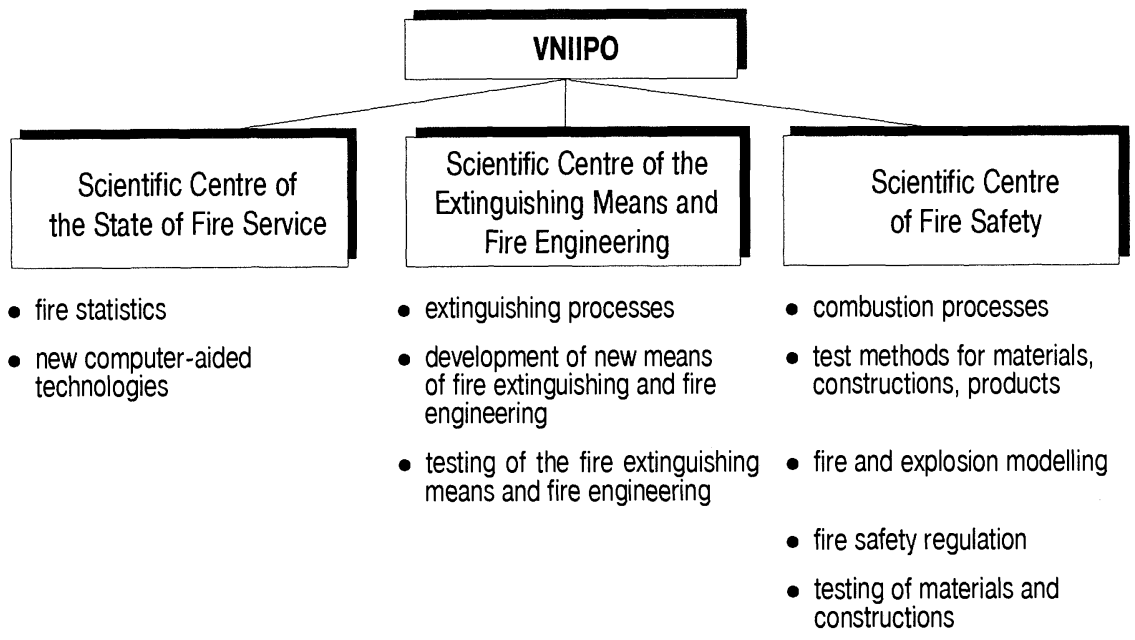


The fire research held in VNIIPO and other Russian Institutes comprises the following scientific directions:

- the research into the burning processes under fire conditions;

- the research into fire and explosion hazard of substances and materials;

- the research into fire resistance of building constructions;

- the study of the mechanism of fire retardance and the development of fire retardant compositions;

- the research into the laws of fire occurrence and development;

- the fire modelling;

- the research into extinguishing processes and development of the new fire extinguishing agents and means;

- the qualitative evaluation of the fire hazard level at the industrial premises and the development of scientific background of the fire norms.

\section{THE RESEARCH INTO THE BURNING PROCESSES UNDER FIRE CONDITIONS}

As a result of the research conducted by Dr. V. Gorshkov and Dr. L. Vogman [1] there was derived an equation describing the conditions of spontaneous ignition of the dispersed materials.

$\frac{Q E C_{o}^{m} \rho r^{2} e^{-E / R T}}{\lambda R T_{k r}^{2}} \cdot \frac{\left(1+\frac{3+n}{B i}\right)}{(1+n)(3+n) \Phi(B i)}-\frac{3 v c R T^{2}}{Q E}=\frac{1}{e}$,

where $Q$ - the thermal effect of the reaction; $E$ - activation energy; $C \delta^{m}$ - oxygen concentration in the surroundings; $m, v$ - the reaction order by the oxidizer and fuel respectively; $\lambda, c, \rho-$ heat conductivity, heat capacity and substance density respectively; $r$ - characteristic dimension; $R$ - universal gas constant; $T$-current temperature in the reaction zone; $n$-characteristic of the symmetrical zone (for the plane-parallel zone $n=0$, for the cylindrical one $n=1$, for the spherical one $n=2)$. In the equation obtained the dependence of the function $\Phi(B i)$ on Biot number $B i$ is defined by the graphical relation. The disagreement between the spontaneous ignition temperatures calculated by the equation (1) and the experimental values does not exceed 3-5 degrees.

The usage of hydrogen as fuel at the electrical power plants, it aircrafts, ships, cars, space rockets necessitated to undertake a research into the safety conditions. For these purposes Prof. V. Makeev [2] studied the main hazards at the emergency spill of the liquid hydrogen: the dimensions of the gas-air cloud, the explosion hazardous mass of hydrogen; the maximal rate of the burning; the critical conditions of the transition of the slow burning into detonation, the excessive pressure in the air shock waves during gas explosion. During the experiments the values of the following parameters varied in the following ranges:

- the mass of the liquid hydrogen spillage from 1 to $2000 \mathrm{~kg}$;

- the volume of the premixed gas mixtures from 0.5 to $310 \mathrm{~m}^{3}$;

- the ignition source energy from 1 to $10^{6} \mathrm{~J}$. 
Owing to the experiments there were derived the simple ratios for the estimation of the volume of the explosion hazardous mixture, the rate of the cloud buoyancy, hydrogen concentration on the visual boundary of the cloud, the factor of hydrogen contribution to explosion:

$V_{\max }=0.43 V_{o}\left[\frac{1}{C_{l}}-\left(1-\frac{T_{o}}{T_{a}}\right)\right] ; \quad M_{\exp }=\frac{106 \rho d^{3}}{\mathrm{Re}^{0.5}} ; \quad \frac{L}{d}=\frac{5.9}{\mathrm{Re}^{0.5} \ln \left(1-C_{m}\right)} ;$

where $V_{\max }$ - maximal volume of explosion hazardous mixture, $V_{o}$ - initial volume of evaporated hydrogen, $C_{l}$-lower flammability limit of hydrogen, $T_{o}$-initial temperature of the cloud, $T_{a}$ - ambient temperature, $M_{\text {exp }}$ - explosion hazardous mass of hydrogen, $\rho$ - average density of hydrogen-air mixture, $d$ - evaporation zone diameter, $\operatorname{Re}=m d / \eta(m-$ mass evaporation rate; $\eta$-dynamic viscosity of hydrogen vapors at $20.4 \mathrm{~K}$ ); $L / d$ - relative distance to any given level of mass hydrogen concentration $C_{m}$.

Experimental results referring to hydrogen and some lower hydrocarbons permitted to derive a generalized dependence of the flame acceleration factor $\varphi\left(\varphi=\left(W_{\max }-U_{n} \sigma\right) / U_{n} \sigma\right)$ on $\operatorname{Re}$ value $\left(\operatorname{Re}=\left(U_{n} r_{o}\right) / v\right)$, where $W_{\max }$ - maximal visual flame velocity; $U_{n}$ - burning velocity; $r_{o}$ - initial radius of the mixture; $n$ - mixture viscosity; $\sigma$ - combustion products expansion factor. This relation is presented in Fig. 1.

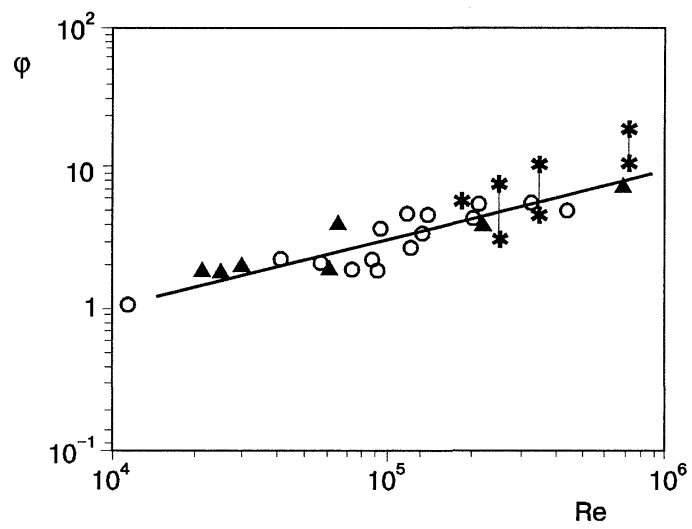

FIGURE 1. Dependence of acceleration factor $\varphi$ on Reynolds number Re: o - hydrogencontaining mixtures; $\boldsymbol{\Lambda}$ - carbon-containing mixtures; $*$ - liquid hydrogen pool

Thus the visual flame velocity on the boundary of the cloud is related to the physical and chemical parameters of the combustible mixture and the initial size of the cloud by the expression:

$W_{\max }=U_{n} \sigma\left(1+0.01 \mathrm{Re}^{0.5}\right)$.

Using the relation (3) one can assess the dimensions of the gas clouds at which a sound level of velocities is reached and a transition to detonation is possible. For hydrogen-air mixtures $r_{0}=$ $70 \mathrm{~m}$, for propane-air mixtures $-3.5 \cdot 10^{3} \mathrm{~m}$, for methane-air mixtures $-5 \cdot 10^{3} \mathrm{~m}$. 
New techniques have been developed to determine burning velocities of gaseous mixtures in spherical bomb by inverse problem method. It is possible to determine effectively the dependence of burning velocity on pressure, temperature and concentration of fuel in mixture. The above mentioned dependences were obtained for various fuels both individual (e.g. methane, propane, hexane, heptane, acetone, isopropanol, benzene) and multicomponent mixtures (e.g. aviation fuels TS-1 and RT). The results of cooperative study of VNIIPO (Dr. V. Molkov) and Institute of Chemical Kinetics and Combustion of Sibirian Branch of RAS (Prof. V. Babkin and Dr. V. Bukharov) on burning velocities of propane-air mixtures in the range of pressures of $1-100 \mathrm{~atm}$, temperatures of $293-500 \mathrm{~K}$, concentrations of propane of 3-6\% by volume are shown in Fig.2. A good compliance with the results of other authors can be stated. It is the most comprehensive data on propane-air mixtures known for us until now. The data can be used for reliable explosion protection systems design for different purposes.

It is necessary to study the dynamics of gaseous deflagration in equipment and buildings of various shapes with real internal obstacles to perform a reliable design of explosion protection systems.

The large-scale experiments were carried out by the personnel of VNIIPO (Prof. Yu. Shebeko) and some other research institutes to study flame acceleration on obstacles. The tube of $100 \mathrm{~m}$ in length and $1.5 \mathrm{~m}$ in diameter closed from one end and opened from another with different types of obstacles was used in one series of experiments. Methane- and propane-air mixtures were studied with ignition both by low-energy (wire) and high-energy (explosives) sources at closed end of the tube. Despite of the high visual flame velocity of up to $800-900 \mathrm{~m} / \mathrm{s}$ no transition from deflagration to detonation was observed in experiments. The linear dependence of visual distance passed by the flame was found. It was explained qualitatively by the formation of a long flame "tongue".

Another series of experiments was carried out by Prof. Shebeko's team with local hydrogen-air mixtures of different composition in $20 \mathrm{~m}^{3}$ vessel with internal obstacles. It was shown that for lean mixtures with concentration of hydrogen of about $10 \%$ by volume the presence of obstacles of used type would result in decrease of pressure both in closed and vented vessels. The reason of it is enclosed in increase of heat loss rate from combustion products to obstacles which is a prevailing process under increase of heat release rate due to flame front enlargement. For most dangerous near stoichiometric $30 \%$ hydrogen-air mixtures only increase of maximum explosion pressure and rate of pressure rise was observed.

Acceleration of gaseous combustion during vented deflagration in different vessels and buildings of up to $8000 \mathrm{~m}^{3}$ in volume was investigated by Dr. V. Molkov. Experiments with propane-air mixtures in $11 \mathrm{~m}^{3}$ vessel with different numbers of various types of grids definitely showed that the explosion overpressure correlated with the proposed theory not only with turbulence factor (the ratio of real flame front area inside the vessel to the surface area of sphere to which combustion products could be collected at the same moment) but with the ratio of turbulence factor to discharge coefficient called as effective turbulence factor. The introduction of obstacles into $11 \mathrm{~m}^{3}$ vessel lead to increase of turbulence factor from 5 to 50 . A corresponding increase of effective turbulence factor is considerably less - from 8 to 16 because of "unusual" increase of discharge coefficient from 0.6 to about 3.0. The value of effective 


\section{Burning velocity of propane-air mixtures:}

\section{Dependence on Pressure, Temperature and Mixture Composition}
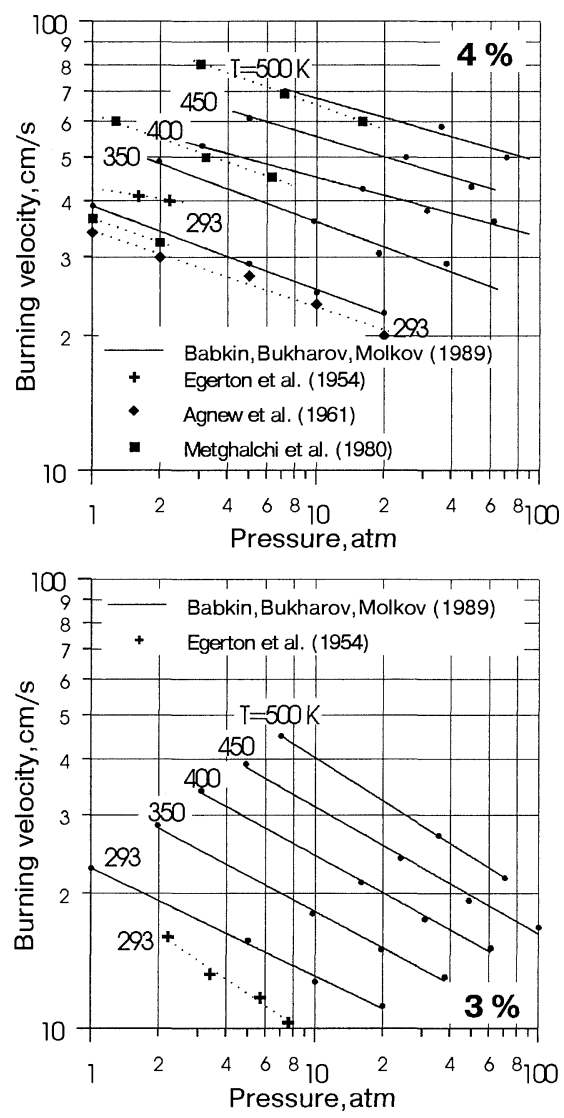

FIGURE 2.
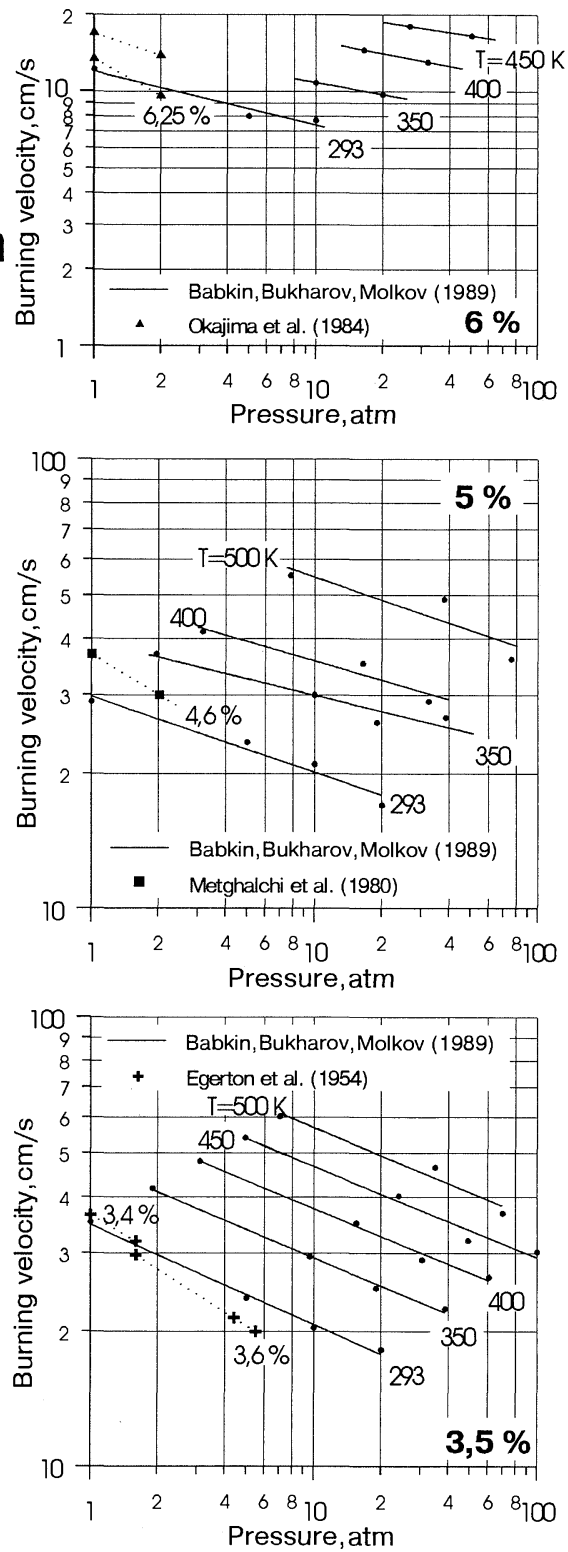
turbulence factor for experiments in $4000 \mathrm{~m}^{3}$ installation of Harrison and Eyre (1987) with obstacles is higher - up to 100 and depends on type of ignition (point or jet ignition). The correlation between explosion overpressure and turbulent venting parameter $W_{t}$ is shown in Fig.3.

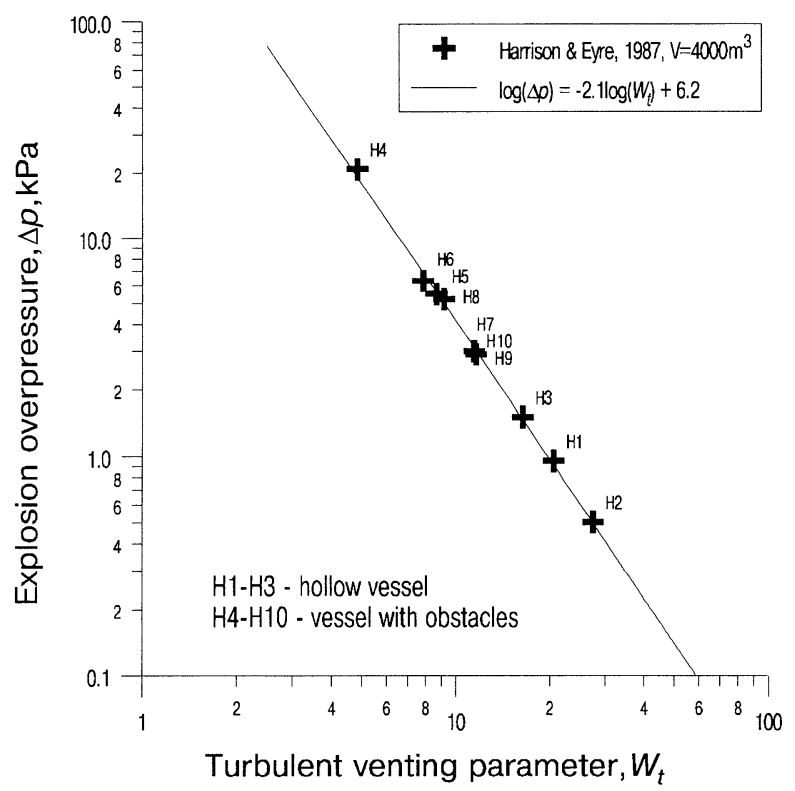

FIGURE 3.

\section{RESEARCH INTO FIRE AND EXPLOSION HAZARD OF SUBSTANCES AND MATERIALS}

The system of assessment of fire and explosion hazard of substances and materials adopted in Russia is specified in standard GOST 12.1.044-89 'Fire and Explosion Hazard of Substances and Materials. Nomenclature of Indices and Methods of Their Determination'.

There are more than 50 indices for gases, liquids, solids and dusts characterizing the conditions of their ignition and burning (about 20 of them are standardized): the flash point, the ignition temperature, the autoignition temperature and others. The majority of these indices are measured according to the methods recommended by International Organization for Standardization (ISO), International Electrotecnical Committee (IEC). Some methods developed by Russian experts have no analogy in other countries.

Prof. Baratov's [3] research results, for example, showed that the objective data concerning the concentration flammability limits can be obtained in the vessel of at least $300 \mathrm{~mm}$ in diameter and at least $800 \mathrm{~mm}$ in height. The determination of the flammability limits in this testing apparatus allowed to correct the available data on the non-combustibility of some mixtures. These results are given in Table 2 . 
TABLE 2. Comparison of the experimental flammability limits obtained in Coward/Jones test apparatus and in Baratov's test apparatus

\begin{tabular}{|l|c|c|c|c|}
\hline \multirow{2}{*}{ Compound } & \multicolumn{2}{|c|}{$\begin{array}{c}\text { Flammability Limits measured in } \\
\text { Coward/Jones test apparatus }\end{array}$} & \multicolumn{2}{c|}{$\begin{array}{c}\text { Flammability Limits measured in } \\
\text { Baratov's test apparatus }\end{array}$} \\
\cline { 2 - 5 } & lower & upper & lower & upper \\
\hline Methyl bromide & no & no & 12.70 & 15.8 \\
\hline Methylene-chloride & no & no & 14.0 & 19.0 \\
\hline Ethyl-bromide & no & no & 6.0 & 10.0 \\
\hline 1-fluoro-1,1-dichloro-ethane & no & no & 8.05 & 15.1 \\
\hline Isopropyl chloride & 3.05 & 9.55 & 2.55 & 10.4 \\
\hline Allyl bromide & 4.36 & 7.25 & 3.85 & 8.5 \\
\hline Propylene & 2.40 & 10.3 & 2.22 & 11.4 \\
\hline
\end{tabular}

The results of the comparative study of the conditions of smoke production during the combustion of materials in the rooms of various volume allowed to specify the requirements towards the small-scale method for the determination of smoke production coefficient. The testing chamber (Fig.4) constitutes a cubical vessel with the rib of $800 \mathrm{~mm}$. The samples are fired in a removable chamber in two regimes: the flaming combustion and smouldering.

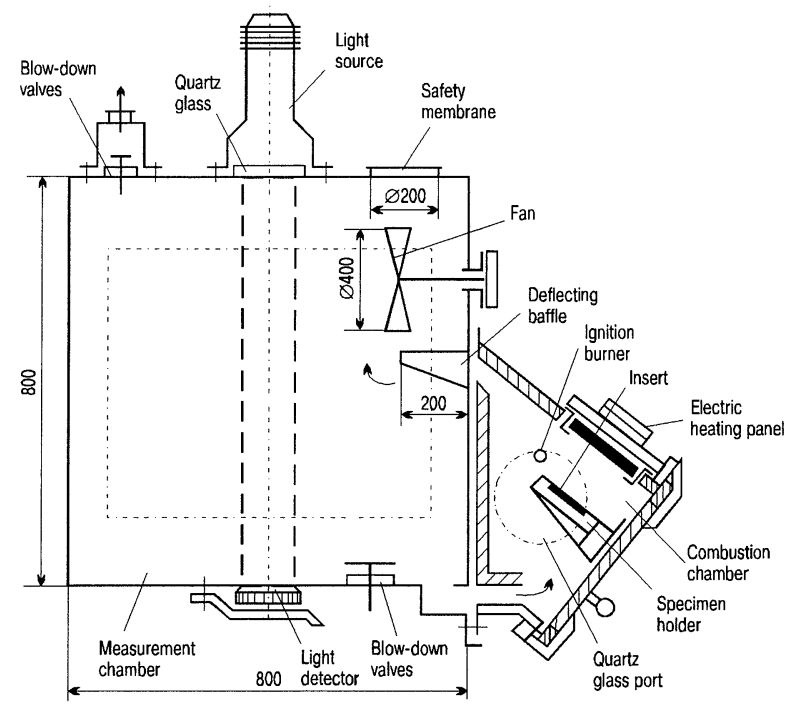

FIGURE 4. The scheme of the test apparatus designed to determine the smoke production coefficient

The maximal value of the smoke production factor obtained in one of these regimes is taken as a final result. 
Combustion products toxicity is estimated by a biological procedure involving the test apparatus shown in Figure 5.

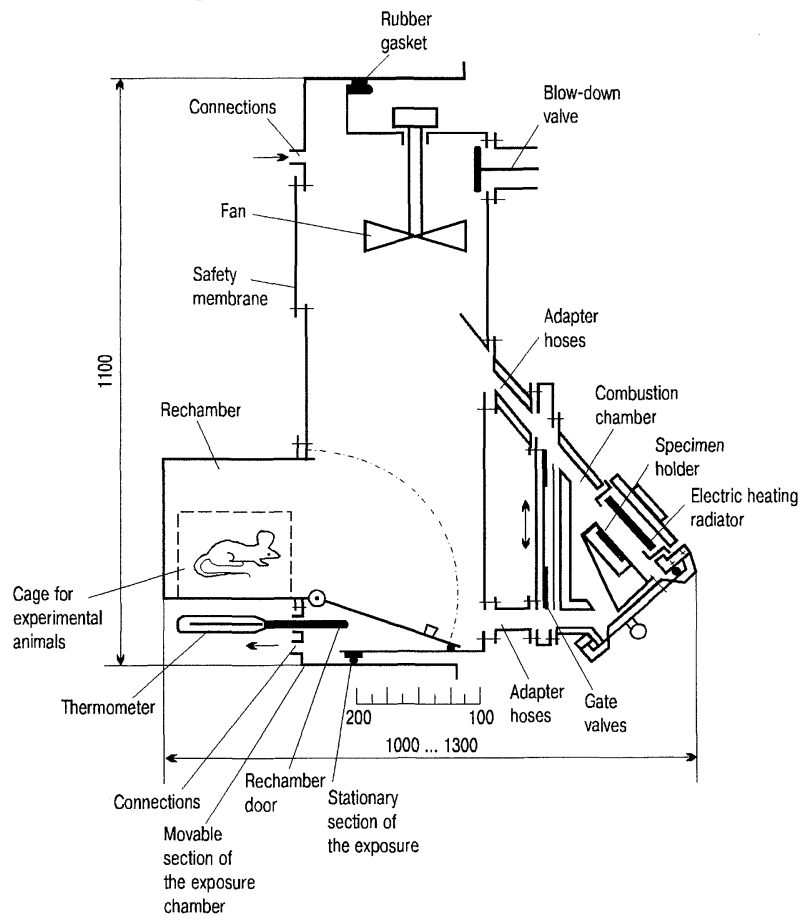

FIGURE 5. The scheme of the test apparatus designed to assess combustion products toxicity

In the combustion chamber the firing of the material is executed. The combustion products affect the white mice placed into the exposure chamber. During the experiments the gaseous medium composition is permanently controlled.

According to the technique above mentioned Dr. V. Ilichkin [4] investigated the influence of the hyperbaric medium on the combustion products toxicity of the polymeric materails. There was found that the following common mechanism: with the increase in pressure from 0.1 to $0.4 \mathrm{MPa}$ and in oxygen concentration from 19 to $25 \%$ by volume the combustion products toxicity decreases in linear or quadratic function way.

\section{LONG-TERM RESEARCH ON VENTING OF DEFLAGRATIONS}

Venting is the most prevalent technique to rescue premises and mitigate losses caused by unwanted gaseous explosions. The comprehensive research into venting of gaseous deflagration was performed by the team under the leadership of Dr. V. Molkov during 1980-1996. The experimental data refer to different configurations of practical interest. 
Much of the work on gaseous explosions appears to have fallen in one of two broad categories: either it has been concentrated on the development of sophisticated models, which are usually too complex for the most of practical applications; or it has provided simple empirical generalizations of experimental results. There is a third approach which is the most fruitful and not often utilized to its fullest potential. It involves the reasonable use of modeling to provide better interpretations of and to extract additional information from the test data. This approach is known as "inverse problem method" that has been the driving force behind our work on venting of deflagrations.

When the team started studies on this subject, most researchers in the world would believe that the peak pressure at a specific gaseous explosion could not be uniquely determined even if all conditions were fixed. Results of long-term research have partly denied such belief, although there remains a difficulty in the process of determination of the turbulence factor.

A lumped parameter model has been developed, which is able to simulate the pressure-time behaviour in vented enclosures, when suitable values are assigned for two parameters, namely the discharge coefficient $\mu$ and a turbulence factor $\chi$. The last one accounts for the difference between the real flame surface and a surface of reference flame, usually a spherical and a laminar one. A great amount of experimental data has been used to identify the best values of those adjustable parameters and an attempt has been made to correlate the turbulence factor to some explosion variables (i.e. vessel volume, vent ratio, dimensionless explosion pressure in closed and in vented vessels). This approach permitted to formulate questions in coupling the research on turbulent combustion with gas dynamics.

Such modeling technique still represents a valuable tool for design purposes, since the more recent attempts for a more detailed modeling, based on a distributed parameter approach, have failed to catch their main objective until now, namely the development of predictive model.

The long-term investigations permitted to establish universal correlation between dimensionless reduced pressure and turbulent venting parameter. The presentation on this theme will be performed by Dr. V. Molkov during this Symposium. The proposed universal correlation is clearly useful for design of residential buildings or industrial facilities where flammable gases are treated or consumed and it can be used by engineers.

The research was concentrated also on an important aspect of the progress of vented gas explosions, as it relates to the enhancement of the rate of combustion due to the presence of obstacles or to the onset of flame instabilities. This is, at the same time, a very important phenomenon, because of its practical implication in the sizing of protection systems, and one that is very difficult to model. The methodology has been developed to quantify these flame acceleration (increase of flame front surface) effects for different combustion systems and geometries.

The effects of the vent cover inertia, of an exhaust duct to a receiver and of water sprinkling have been studied. 


\section{FIRE MODELLING}

Data on main activities in mathematical fire modelling are presented in Table 3.

Table 3. Researches in mathematical fire modelling

\begin{tabular}{|l||l|c|c|}
\hline \multicolumn{1}{|c|}{ Object of modelling } & \multicolumn{1}{|c|}{ Authors } & Year & References \\
\hline Fire in a room & V. Astapenko, Yu. Koshmarov, I. Molchadsky & 1988 & {$[7]$} \\
& A. Ryzhov & 1991 & {$[5]$} \\
& & 1994 & {$[6]$} \\
\hline $\begin{array}{l}\text { Fire in a room with regard to } \\
\text { extinguishing }\end{array}$ & A. Ryzhov & 1995 & {$[8]$} \\
\hline Fire in a building & V. Gutov, V. Litskevich & 1994 & {$[9]$} \\
\hline Explosion in equipment and building & V. Molkov & 1996 & {$[10]$} \\
& A. Mishuev, V. Kazennov, A Komarov & 1996 & {$[11]$} \\
\hline Fire in a subway & V. Il'in & 1994 & {$[12]$} \\
\hline Fire in atmosphere (large-scale fire) & A. Ryzhov, Yu. Gostintsev & 1993 & {$[13]$} \\
\hline
\end{tabular}

Fire models for rooms [5-8] were created on the base of complete non-stationary Navier-Stokes equations, energy conservation equation and equation for conservation of reacting components concentrations. Heat-and-mass transfer processes and combustion processes in rooms are assumed to be two-dimensional plane or two-dimensional axisymmetrical. Fire seat is modelled as a volume (fixed or variable) heat source. In modelling the mass rate of combustion reaction is assumed to be determined by the diffusion processes for fuel vapours and oxygen and dependent on their average concentrations, as well as whirl dissipation energy and kinetic energy of turbulence. To test the developed mathematical models the experimental data of the authors were used. Calculated temperature fields, calculated temperature maximum and calculated optical density of smoke near the ceiling and at the outlet of the openings satisfactorily agree with experimental data.

The mathematical modelling of fire dynamics is developed with regard to extinguishing agents contribution to fire growth [8]. The model of interaction for gas aerosol extinguishing agents and fire seat for ethanol and heptane burning is developed. The influence of the fire seat location on the extinguishing agent concentration distribution within the experimental chamber has been taken into account.

When modelling large fires in atmosphere [12] the combustion processes in gaseous phase under conditions of natural convection are taken into account. Mathematical models of large fires are developed on the base of complete Navier-Stokes equations for viscous compressible gas. Algebraic turbulence models are used to describe of turbulence processes.

A general approach is applied for the modelling of open flames, fire balls and fire whirls, that is: fuel vapours injection into combustion zone is performed at the prescribed volume rate of mass release in the volumes adjacent to the surfaces of the burning substances. 
As a result of the numerical experiments such fire formations in atmosphere as fire whirls were obtained. There was found out the following:

- flames in fire whirls have the form of vertical cylindrical columns;

- as compared with free flames the significant increase of flame height in fire whirls is confirmed (at least in two times);

- the combustion inside small fire whirls (with the diameter of less than $1,4 \mathrm{~m}$ ) occurs with the excess of fuel vapours in contrast to similar free flames where combustion occurs with the excess of oxygen;

- the overpressure in fire whirls has a small value.

At present the creation of mathematical analog for physical-chemical description of fire growth in the room is mainly completed. The further studies are realized in two directions: development of mathematical programs and scientific research into unique conditions for fire growth. The research related to fire origin (fire load) and conditions of heat transfer between fire origin and differently oriented building constructions are determinative in this part of study.

The solution of two-dimensional Fourier equation permitted to obtain a generalized relationship for fire propagation along the surface of fire load depending on heat release rate and conditions of heat effects on the surface. The method of replacement of fixed coordinates for non-stationary coordinates that have the velocity equal to the velocity of fire propagation was used in the solution.

$$
\frac{U \delta}{a}=\frac{1}{2} \frac{\mu M Q_{l}}{\frac{\lambda}{\delta}\left(T_{b}-T_{1}\right)}+\frac{1}{2} \frac{q_{e f}}{\frac{\lambda}{\delta}\left(T_{b}-T_{1}\right)}-\frac{T_{b}-T_{2}}{T_{b}-T_{1}} \frac{1}{\frac{1}{2} \frac{R_{o}}{R_{m}}+1},
$$

where $U$ - fire spread rate, $\mathrm{m} \cdot \mathrm{s}^{-1} ; \delta$ - thickness of material, $\mathrm{m}$; for thermally thick material

$\delta=\left[\frac{2 a_{1}\left(T_{b}-T_{1}\right)}{T_{1}} t\right]^{1 / 2} ;$

$a_{1}$ - thermal diffusivity of material, $\mathrm{m}^{2} \cdot \mathrm{s}^{-1} ; T_{b}$ - ignition temperature of material; $T_{1}$ - initial temperature of material; $t$ - time required for heating of material to the temperature $T$ equal to $T_{b}$ and time of structure heating at fire spread on its surface on a distance $l=a / U ; \eta-$ combustion completeness of material; $M-$ mass loss rate for material, $\mathrm{kg} \cdot \mathrm{m}^{-2} \cdot \mathrm{s}^{-2} ; Q_{l}$ - the lowest heat of combustion of material, $\mathrm{J} / \mathrm{kg} ; \lambda$ - thermal conductivity of material, $\mathrm{W} \cdot \mathrm{m}^{-1} \cdot \mathrm{K}^{-1}$; $q_{e f}$-thermal radiation intensity on a surface of material on a heating distance $l$ (reaction zone), $\mathrm{W} \cdot \mathrm{m}^{-2} ; T_{2}$ - temperature of material behind of heating zone of base material, $\mathrm{K} ; R_{O}=h / \lambda_{2}-$ thermal resistance of base material;

$h=\left[\frac{2 a\left(T_{b}-T_{2}\right)}{T_{2}} t\right]^{1 / 2}-\delta ;$

$R_{m}=\delta / \lambda_{1}-$ thermal resistance of combustible material; 
$a=\frac{(h+\delta)^{2}}{\left(R_{m}+R_{o}\right)\left(\rho_{1} \delta C p_{1}+\rho_{2} h C p_{2}\right)} ;$

$a$ - thermal diffusivity of combustible material; $\rho_{1}, \rho_{2}$ - densities of combustible and base materials respectively, $\mathrm{kg} \cdot \mathrm{m}^{-3} ; C p_{1}, C p_{2}$ - heat capacities of combustible and base materials, $\mathrm{J} \cdot \mathrm{kg}^{-1} \cdot \mathrm{K}^{-1}$.

Equation (4) relates two fundamental parameters, namely, fire spread rate and heat release in burning materials $\left(\mu M Q_{l}\right)$ through heat transfer conditions $\left(q_{e j}\right)$.

Investigations into heat exchange process were carried out between a fire seat and building materials at the initial fire stage both in a local and developed fire.

Solution of boundary layer integral equations for vertical constructions and that of equations defining thermal and hydrodynamic spray interaction with a horizontal barrier resulted in criteria relationships for heat exchange conditions being useful for practical fire resistance problems.

For instance, one can determine a dimensionless coefficient of heat transfer, $N u$, for a complex heat exchange along vertical constructions during turbulent natural convection from the expression:

$N u=0.2\left(G r_{\alpha} \cdot P r\right)^{1 / 3}\left[\frac{P r^{2 / 3}}{2.14\left(1+N_{t}\right)+P r^{2 / 3}}\right]^{1 / 3}\left(1+N_{t}\right) ;$

where $N u=L x / \lambda$ - Nusselt number; $L$ - heat exchange coefficient, $\mathrm{W} \cdot \mathrm{m}^{-2} \cdot \mathrm{K}^{-1} ; x$ - determining size (length of combustible material), $\mathrm{m} ; \lambda$ - thermal conductivity of material of structure, $\mathrm{W} \cdot \mathrm{m}^{-1} \cdot \mathrm{K}^{-1}$

$G r_{\alpha}=\frac{g \beta\left(T_{e v}-T_{w}\right) x^{3}}{v^{2}}-$ Grasskoff number;

$N_{t}=\frac{16 n^{2} \sigma}{3 B u \lambda_{T}} \delta_{t}\left(T_{w}^{3}\right)-$ the term describing thermal conductivity and radiation;

$\operatorname{Pr}$ - Prandtle number; $n$ - refraction coefficient $(\mathrm{n} \approx 1)$ of gaseous environment; $\lambda_{T}$-turbulent thermal conductivity, $\mathrm{W} \cdot \mathrm{m}^{-1} \cdot \mathrm{K}^{-1} ; \sigma=5.75 \cdot 10^{-8} \mathrm{~W} \cdot \mathrm{m}^{-2} \cdot \mathrm{K}^{-4}$ - Stephane-Bolzman constant; $\delta_{t}$ thickness of thermal boundary layer, $\mathrm{m} ; B u=k_{\delta} \delta_{t}$ - Buger number; $k \delta$ - absorption coefficient of the boundary layer, $\mathrm{m}^{-1} ; T_{w}$ - surface temperature of structure, $\mathrm{K}$.

\section{INVESTIGATION INTO FIRE EXTINGUISHMENT PROCESSES}

Fire extinguishment process research currently performed in Russia is aimed to solve the following main problems:

- search for halon substitutes employed in total flooding systems; 
- improved extinguishing efficiency of large pools with oil, oil products, alcohol, benzine/alcohol mixtures;

- search for methods of extinguishing large spills of oil and oil products.

In solving the first problem solid fuel compositions have been formulated which while burning form gas aerosol compositions showing a high extinguishing efficiency.

Solid fuel composition in their original state contain inorganic oxidizers $\left(\mathrm{KNO}_{3} ; \mathrm{KClO} 4 \mathrm{KCl}\right)$ and organic or inorganic reducing agents (epoxide resin, $\mathrm{Mg}$ ). On burning similar compositions generate gas aerosol compositions, gas phase of which consists mainly of $\mathrm{N}_{2}$ and $\mathrm{CO}_{2}$, while solid phase contains $\mathrm{K}_{2} \mathrm{CO}_{3}, \mathrm{KHCO}_{3}, \mathrm{KCl}$. The influence of the solid phase upon a flame is similar to fire extinguishing powder, but in doing so it posses a considerably greater efficiency due to a high dispersivity (a characteristic particle size is about 1 micron). Table 4 shows the comparison of fire extinguishing efficiency of halons, powders and gas aerosol compositions.

Table 4. Indices of extinguishing media efficiency

\begin{tabular}{|c|c|c|c|}
\hline \multicolumn{1}{|c||}{$\begin{array}{c}\text { Fire class or inerting } \\
\text { mixture }\end{array}$} & \multicolumn{3}{c|}{ Extinguishing concentration, $\mathrm{g} / \mathrm{m}^{3}$} \\
\cline { 2 - 4 } & halons & powders & gas aerosol composition \\
\hline A & $80-120$ & $400-600$ & $50-100$ \\
\hline B & $200-350$ & 250 & $30-50$ \\
\hline C (hydrogen) & 1300 & 800 & 200 \\
\hline Air gas mixtures, \% vol. & & & 70 \\
$\mathrm{H}_{2}-10$, air - 90 & 870 & 280 & 230 \\
$\mathrm{H}_{2}-20$, air - 80 & 1380 & 770 & $40-80$ \\
\hline
\end{tabular}

The effectiveness of fire extinguishment markedly increases due to a small particle size of an extinguishment, a high specific surface and a small volume contributing to a quick warming-up and flame gasification.

The credit for the solution of the second and third problems should go to Prof. A. Sharovarnikov.

Nowadays fire extinguishment of the following premises presents a real challenge:

- $30000 \mathrm{~m}^{3}$ oil and benzine pools;

- oil and oil products spillage;

- $10000 \mathrm{~m}^{3}$ or more pools with various alcohol/benzine mixtures.

Research performed in Prof. A. Sharovarnikov's laboratory made the following solutions possible:

- method of extinguishing large pools using the 'Selfservis' system;

- 'Apres' composition for preventing spillage and boiling of oil at a long-term burning; 
- 'Fast foam $2 \times 2 \times 3$ ' liquids (fast dissolving nonviscous liquids) for liquidation of benzine/alcohol and alcohol fires in large pools;

- 'Oilgermetic' media for preventing evaporation and burning of oil products at emergency spills;

- 'Guk-2' water compositions being flexible in the form to provide the discharge of compact water sprays at a distance of more than $100 \mathrm{~m}$ and $40-50 \mathrm{~m}$ along the vertical.

The novelty of 'Selfservis' technology lies in a very fast composition discharge within a short period of time. Without damage the medium reaches an oil product surface and penetrates the most difficult-to-reach, closed from above sectors of the surface. Simultaneous generation of foaming emulsion under the whole burning surface together with a high foam discharge rate allows its usage for protecting pools with any surface area and roof type.

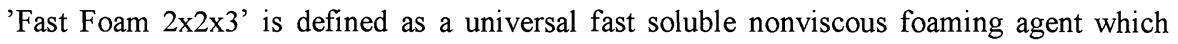
enables one to solve the problem of alcohol fire extinguishment in pools having a volume of $10000 \mathrm{~m}^{3}$ and more. Fire is put out without thinning alcohol with water.

\section{CONCLUSIONS}

The present lecture doesn't pretend to the comprehensive review of all fire safety researches in Russia. Only some main directions of the research that are currently performed in institutions submitted to the Ministry of the Interior, in the institutes of the Russian Academy of Sciences and in the universities of higher education are described here.

For the last years together with state organizations some private firms that work out new fire extinguishing agents, new flame retardance measures and work in the field of fire insurance joined the process of fire safety problems study. Though their success in the field of theory development is not so great as the state organizations did, the volumes of their investigations annually increase.

To the last time the results of Russian scientists' investigations were less known abroad. We hope that our participation in IAFSS, the organization of international seminars and conferences in Russia will permit our colleagues to get more complete information about the level and direction of our researches. We are looking forward to international cooperation in fire safety science field.

\section{REFERENCES}

1. V.I. Gorshkov, L.P. Vogman, A.G. Degtjarov. Approximate problem solution of dispersive materials self-ignition for the V-th order reaction. Fire-and-Explosion Safety, 1993, no 1, pp. 25-28.

2. V.I. Makeev. Safety of premises with liquid cryogenic products. Fire-and-Explosion Safety, 1992, no 3, pp. 34-35.

3. V.N. Krivulin, Yu.N. Shebeko, V.L. Pavlova, E.A. Kudrjavtsev, A.N. Baratov. Investigation into concentration flame spread limits in mixtures of halogen hydrocarbon vapours with air. Chemical physics, 1984, v.3, no 12, pp. 1745-1749. 
4. N.S. Ilitchkin, M.V. Yanenko, P.A. Evarestov. Influence of hyperbaric fluid factors upon emission and toxic effect of material combustion products. Fire-and-Explosion Safety, 1994, no 3, pp. 13-18.

5. A.M. Ryzhov. Mathematical modelling of fires in compartments in view of combustion under natural convection conditions. Combustion and Explosion Physics, 1991, v.27, no.3.

6. A.M. Ryzhov. Differential modelling of dynamics of spreading fires and their hazardous factors in compartments. Fire-and-Explosion Safety, 1994, v.3, no 4, pp. 21-34.

7. V.M. Astapenko, Yu. A. Koshmarov, I.S. Molchadsky, A.N. Shevljakov. Thermogas Dynamics of Fires in Compartments, - M., Stroiizdat, 1988. - 448 p.

8. A.M. Ryzhov. Modelling of fires and fire extinction in compartments. Fire and Explosion Hazard of Substances and Venting of Deflagrations. Proc. of the First Int. Seminar, M., $1995,-$ p.269-280.

9. V.N. Gutov, V.V. Litskevitch. Mathematical model of spreading flame burning in a building. Fire-and-Explosion Safety, 1994, no 4, pp. 58-65.

10. V.V. Molkov. Theoretical Generalization of International Experimental Data on Vented Gas Explosion Dynamics. - Proceedings of the First International Seminar on Fire and Explosion Hazard of Substances and Venting of Deflagrations (Moscow, 17-21 July 1995), All-Russian Research Institute for Fire Protection, 1996, pp. 166-181.

11. A.V. Mishuev, V.V. Kazennov, A.A. Komarov. Modelling of Dynamic loads effecting building structures at an emergency explosion of air/gas mixtures inside a building. Fire-and-Explosion Safety, 1996, no 1, pp. 34-40.

12. V.V. Iljiin. Main principles of physical modelling of fires in metro. Fire-and-Explosion Safety, 1994, no 3, pp. 37-44.

13. A.M. Ryzhov, Yu. A. Gostintsev. Mathematical modelling of fire formations in open space fires. Fire-and-Explosion Safety, 1993, no 1, pp. 3-16. 
